\title{
Ecofriendly green biosynthesized of metallic nanoparticles: Bio-reduction mechanism, characterization and pharmaceutical applications in biotechnology industry
}

\author{
Loutfy H Madkour \\ Chemistry Department, Faculty of Science and Arts, Baljarashi, Al Baha University, Baljarashi 65635, Saudi Arabia
}

\begin{abstract}
Biomolecules of live plants, plant extracts and microorganisms such as bacteria, fungi, seaweeds, actinomycetes, algae and microalgae can be used to reduce metal ions to nanoparticles. Biosynthesized nanoparticle effectively controlled oxidative stress, genotoxicity and apoptosis related changes. Green biosynthesized NPs is alternative methods, which is hydrophilic, biocompatible, non-toxic, and used for coating many metal NPs with interesting morphologies and varied sizes. The reducing agents involved include various water-soluble plant metabolites (e.g. alkaloids, phenolic compounds, terpenoids, flavonoids, saponins, steroids, tannins and other nutritional compounds) and co-enzymes. The polysaccharides, proteins and lipids present in the algal membranes act as capping agents and thus limit using of non-biodegradable commercial surfactants. Metallic NPs viz. cobalt, copper, silver, gold, platinum, zirconium, palladium, iron, cadmium and metal oxides such as titanium oxide, zinc oxide, magnetite, etc. have been the particular focus of biosynthesis. Bio-reduction mechanisms, characterization, commercial, pharmacological and biomedical applications of biosynthesized nanoparticles are reviewed.
\end{abstract}

\section{Introduction}

It relies on the synthesis and modulation of nanoparticles, which requires significant modifications of the properties of metals [1]. Recently, the diverse applications of metal nanoparticles have been explored in biomedical, agricultural, environmental, and physiochemical areas [1,2]. A Japanese researcher, Norio Taniguchi, first introduced Nanotechnology [3]. Use of Microreaction Technology (MRT) may lower product cost of goods and increases yield and throughput of a manufacturing facility. This technology is able to perform hazardous, high temperature and pressure reactions, as well as those containing unstable or extremely reactive elements. Using MRT, these types of reactions can be safely operated under intensified process conditions. Since the initiation of using MRT in 2003, it has invested millions CHF in improving its continuous flow technologies, facilities, people and know-how to help redefine the future standards of chemical manufacturing. A full line of Development and Manufacturing Capabilities using the Microreaction Technology Platform can be offered. This technology enables new processing that could not have been performed under batch conditions. Known as Flash Chemistry, this approach, which is based on high-resolution reaction time control, serves as a powerful tool for synthesis of organic compounds. Multiple steps of a traditional chemical process can be replaced by a single Flash Chemistry step, which leads to shorter synthetic routes. By shortening reaction routes, we are able to reduce processing time and ultimately reduce cost of goods. Use of flow chemistry also creates processes that are inherently safer due to the higher level of containment.

Nanoparticles are of great scientific interest as they bridge the gap between bulk materials and atomic or molecular structures. Change in size can change the physical and chemical properties. The application of metal nanoparticles is very common due to their wide applications in various industries [4]. NPs with control over particle size shape and crystalline nature has been one of the main objectives in chemistry that could be used for potential applications, such as bio-medical, biosensor, catalyst for bacterial biotoxin elimination and lower cost electrode. NPs having at least one dimension less than $100 \mathrm{~nm}$ such as nanosheets; nanotubes and nanowires have gained much attention because of their promising applications [5]. The findings of the present review reveals an eco-friendly, quite rapid and cost-effective biogenic synthesis protocol to synthesize metallic nanoparticles NPs using plants extracts and microorganisms. Characterization and properties of NPs are studied. Pharmacological, biomedical and environmental applications of NPs are reviewed. Nanoparticles have proved to be a likely candidate for antimicrobial, anti-bactericidal and anti-fungicidal activities agents. Cytotoxic drugs act by directly killing selected cells, affecting both the growth and behavior of remaining cells to treat unwanted malignancies and tumors. Cytotoxic can be used to treat various ailments including rheumatoid arthritis, and systemic lupus erythematous. They are commonly used in oncology therapeutics, which represent one of the fastest growing segments of the pharmaceutical and biotechnology industry. While cytotoxic drugs have widespread treatment potential, the successful and safe manufacturing of cytotoxic drugs requires a highly skilled team of experts and well controlled manufacturing facilities.

Correspondence to: Loutfy $\mathrm{H}$ Madkour, Chemistry Department, Faculty of Science and Arts, Baljarashi, Al Baha University, Baljarashi 65635, Saudi Arabia, E-mail: Lmadkour@bu.edu.sa

Key words: nanoparticles, biological synthesis, bio-reduction mechanism, commercial applications, pharmacological applications, biomedical applications

Received: January 08, 2018; Accepted: January 19, 2018; Published: January 24, 2018 
Madkour LH (2018) Ecofriendly green biosynthesized of metallic nanoparticles: Bio-reduction mechanism, characterization and pharmaceutical applications in biotechnology industry

In conclusion, green biogenic metallic nanoparticles may be considered as a potent cytotoxic, apoptotic and novel, effective drug against microbes. Therefore, they are good candidate for applications including medical, catalysis, electrochemistry, biotechnology, and trace-substance detection.

\section{Principles of green biosynthesized chemistry}

\section{Many of the Principles of Green Biosynthesized Chemistry:}

- Prevention

- Atom Economy

- Less Hazardous Chemical Syntheses

- Safer Solvents and Auxiliaries

- Design for Energy Efficiency

- Reduce Derivatives

- Catalysis

- Inherently Safer

The following list outlines an early conception of what would make a greener chemical, process, or product.

1. Prevention: It is better to prevent waste than to treat or clean up waste after it has been created.

2. Atom Economy: Synthetic methods should be designed to maximize the incorporation of all materials used in the process into the final product.

3. Less Hazardous Chemical Syntheses: Wherever practicable, synthetic methods should be designed to use and generate substances that possess little or no toxicity to human health and the environment.

4. Designing Safer Chemicals: Chemical products should be designed to affect their desired function while minimizing their toxicity.

5. Safer Solvents and Auxiliaries: The use of auxiliary substances (e.g., solvents, separation agents, etc.) should be made unnecessary wherever possible and innocuous when used.

6. Design for Energy Efficiency: Energy requirements of chemical processes should be recognized for their environmental and economic impacts and should be minimized. If possible, synthetic methods should be conducted at ambient temperature and pressure.

7. Use of Renewable Feedstock's: A raw material or feedstock should be renewable rather than depleting whenever technically and economically practicable.

8. Reduce Derivatives: Unnecessary derivatization (use of blocking groups, protection/ deprotection, temporary modification of physical/chemical processes) should be minimized or avoided if possible, because such steps require additional reagents and can generate waste.

9. Catalysis: Catalytic reagents (as selective as possible) are superior to stoichiometric reagents.

10.Anastas, P. T.; Warner, J. C. Green Chemistry: Theory and Practice, Oxford University Press: New York, 1998; by permission of Oxford University Press.
11.Design for Degradation: Chemical products should be designed so that at the end of their function they break down into innocuous degradation products and do not persist in the environment.

12.Real-time analysis for Pollution Prevention: Analytical methodologies need to be further developed to allow for realtime, in-process monitoring and control prior to the formation of hazardous substances.

13.Inherently Safer Chemistry for Accident Prevention: Substances and the form of a substance used in a chemical process should be chosen to minimize the potential for chemical accidents, including releases, explosions, and fires.

\section{Methods and synthesis technologies}

Using and developing advanced chemical technologies that allow delivering superior products and services to customers. Working with a variety of chemical product platforms and technologies to help optimize your process to meet your launch timelines and commercial needs. In addition to the Standard Chemical Transformations, many chemical processes involving Wittig, Enzymatic, Emulsion, Organolithium, and Organometallic Reactions and so on. Based on its specific backward integration, it has developed several product platforms with a broad range of products.

\section{Solid material technology}

The physical properties of the solid material such as particle size, flowability or absence of dust become increasingly important as an additional product value. Solid Material Technology Team was established to provide state-of-the art solid technologies. This competence center is focused on the three linked disciplines which contribute to a rapid and competitive processing environment.

- Solid-Liquid Separation

- Particle Forming

- Bulk Power Handling

\section{Plant design}

Designs and constructs new plants with both continuous and batch equipment. There is able to react quickly to the changing technical and market requirements. Multi-purpose plants are modularly designed, allowing them to be quickly and effectively adapted for a wide range of changing product portfolios.

The nature of the plant extract, its concentration, the concentration of the metal salt, the $\mathrm{pH}$, temperature and contact time are known to affect the rate of production of the nanoparticles, their quantity and other characteristics. Biosynthesis reaction can be altered by wide range of metal concentration and amount of plant extract in the reaction medium, it may transform the shapes and size of the nanoparticles.

\section{Preparation of metallic NPs}

The energy and growth rate of a crystal can be controlled by the introduction of a suitable templating agent or a surfactant, which lowers the interfacial energy [6]. The alga caused the reduction of auric chloride solution and the AuNPs were stable in solution, which is important from biological prospective. Au NPs were prepared from this algal biomass with a reaction time of $10 \mathrm{~min}$. This pathway proves to be one of the promising 'green' routes for the synthesis of NPs. They exhibit excellent antimicrobial and antioxidant properties as their surface is functionalized [7]. Prasiola crispa is other freshwater green algae, which 
Madkour LH (2018) Ecofriendly green biosynthesized of metallic nanoparticles: Bio-reduction mechanism, characterization and pharmaceutical applications in biotechnology industry

is used for the one-step biosynthesis of Au NPs in the size range of 5-25 $\mathrm{nm}$ via reduction of chloroauric acid. The synthesis of silver, copper, and zinc nanoparticles using Streptomyces sp. has demonstrated that the reductase enzyme from Streptomyces sp. has a vital role in the reduction of metal salts. Similar to other microorganisms, yeasts have also been widely investigated for the extracellular synthesis of the nanoparticles on a large scale, with straightforward downstream processing [8].

\section{Preparation of metal oxide NPs}

Different synthetic methods such as hydrothermal, solvothermal, microwave, vapor deposition, seed mediated, spray pyrolysis, wetchemical have been employed for the preparation of metal oxide NPs with diverse morphology and size.

Recent report on the synthesis via aqueous extract of brown alga S. muticum has indicated the formation of pure $\mathrm{ZnO}$ NPs in the size range of 30-57 nm with hexagonal crystal structure [9]. Francavilla, et al. designed a feasible protocol for the synthesis of $\mathrm{ZnO}$ NPs using Gracilaria gracilis, an edible form of algae.

Plant crude extract contains novel secondary metabolites such as phenolic acid, flavonoids, alkaloids and terpenoids in which these compounds are mainly responsible for the reduction of ionic into bulk metallic nanoparticles formation as shown in Figure $1[10,11]$. These primary and secondary metabolites are constantly involved in the redox reaction to synthesize eco-friendly nanosized particles.

\section{Nanoparticle synthesis using plants}

Different parts of plants such as Stem [12], seeds [13], leaves [12] and flowers are used to produce silver, gold and many other metallic NPs. Besides microbes, use of part of plants like stem, leaves, roots etc. for the synthesis of nanoparticles is yet another exciting possibility that is relatively unexplored.

\section{Structural transformation in monolayer materials: a $2 \mathrm{D}$ to $1 \mathrm{D}$ transformation}

Kasra, et al. [14] used atomistic simulations and revealed an intrinsic structural transformation in monolayer materials that lowers their dimension from 2D nanosheets to 1D nanostructures Similarly, the chemical methods are used to synthesized NPs by electrodeposition, sol-gel process, chemical solution deposition, chemical vapour deposition, soft chemical method, Langmuir Blodgett method, catalytic route, hydrolysis, co-precipitation method and wet chemical method. Apart from that, the biological methods are using eco-friendly resources such as plant extracts, bacteria, and fungi, micro algae such as cyanobacteria, diatom, seaweed (macroalgae) and enzymes. Various microorganisms, such as bacteria, fungi [15], yeast, plant extracts and waste materials have acted as eco-friendly precursors for the synthesis of NPs with potential applications.

\section{Bio-reduction mechanism}

The methods for making nanoparticles can generally involve either a "top down" approach or a"bottom up" approach. In top-down synthesis (Figure 2), nanoparticles are produced by size reduction from a suitable starting material. Size reduction is achieved by various physical and chemical treatments (Figure 2). Top down production methods introduce imperfections in the surface structure of the product and this is a major limitation because the surface chemistry and the other physical properties of nanoparticles are highly dependent on the surface structure [16].

In bottom up synthesis, the nanoparticles are built from smaller entities, for example by joining atoms, molecules and smaller particles. In bottom up synthesis, the nanostructured building blocks of the nanoparticles are formed first and then assembled to produce the final particle. The bottom up synthesis mostly relies on chemical and biological methods of production. The probable mechanism of nanoparticle synthesis by bottom up approach is shown in Figure 3. Of the biological methods of synthesis, the methods based on microorganisms have been widely reported.

Silver: the biochemical reaction of $\mathrm{AgNO}_{3}$ reacts with plant broth leads to the formation of AgNPs by following reaction [17].

$$
\mathrm{Ag}+\mathrm{NO}_{3}^{-}+\text {Plant extract } \rightarrow \mathrm{Ag}^{\circ} \mathrm{NPs}+\text { byproducts }
$$

Gold: the plant extract contains different biomolecules such as

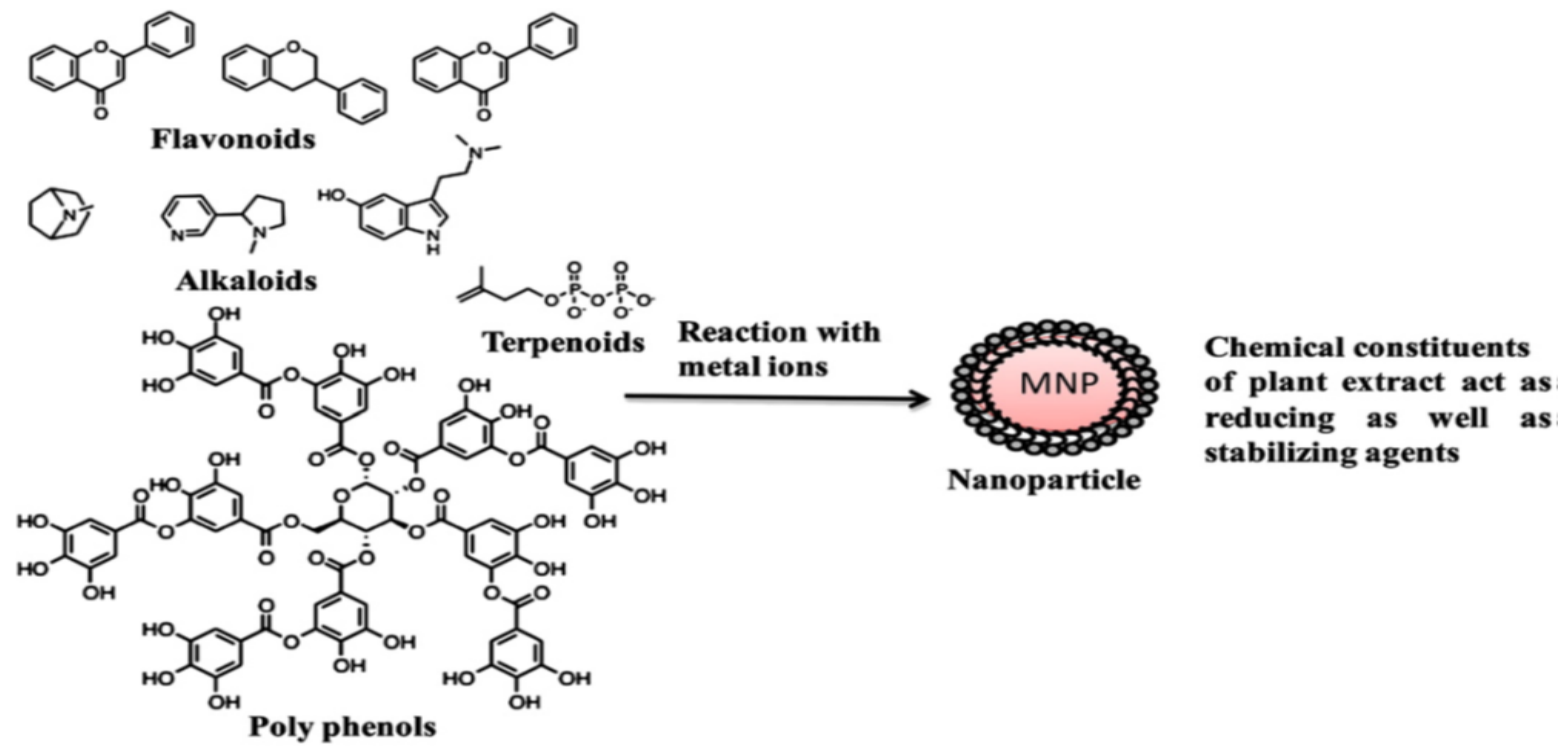

Chemical constituents of plant extract

Figure 1. Possible chemical constituents of plant extract responsible for the bio reduction of metal ions $[10,11]$. 


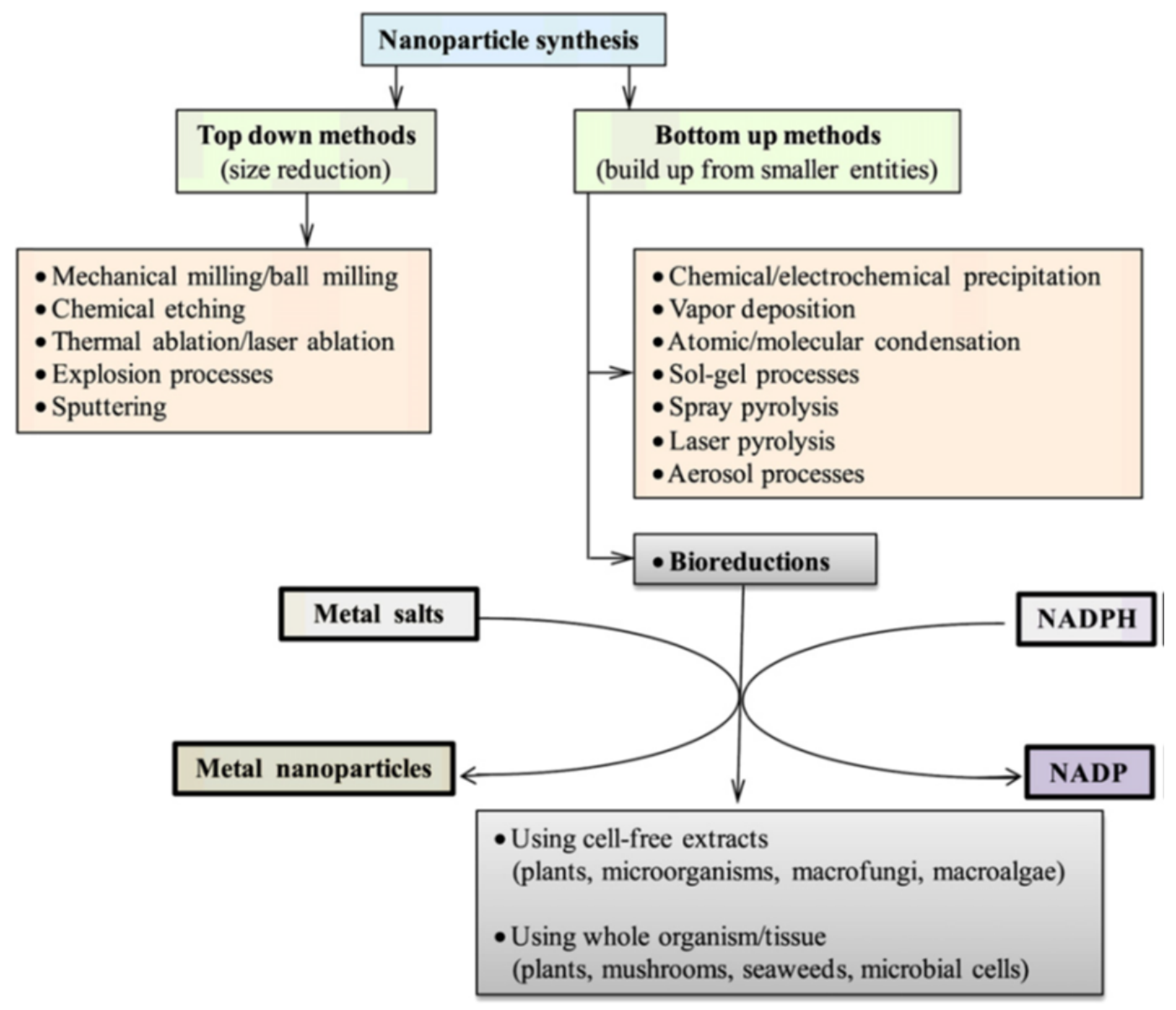

Figure 2. Various approaches for making nanoparticles and cofactor dependent bio-reduction.
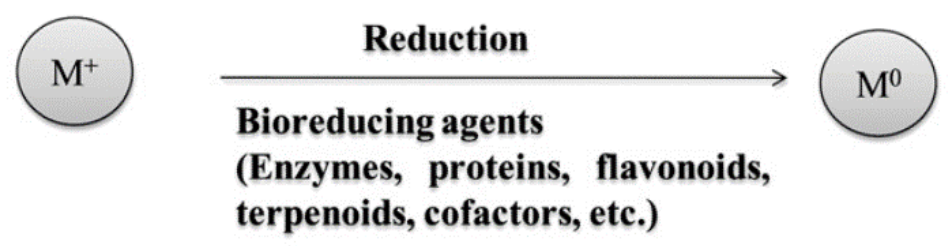

(Enzymes, proteins, flavon
terpenoids, cofactors, etc.)

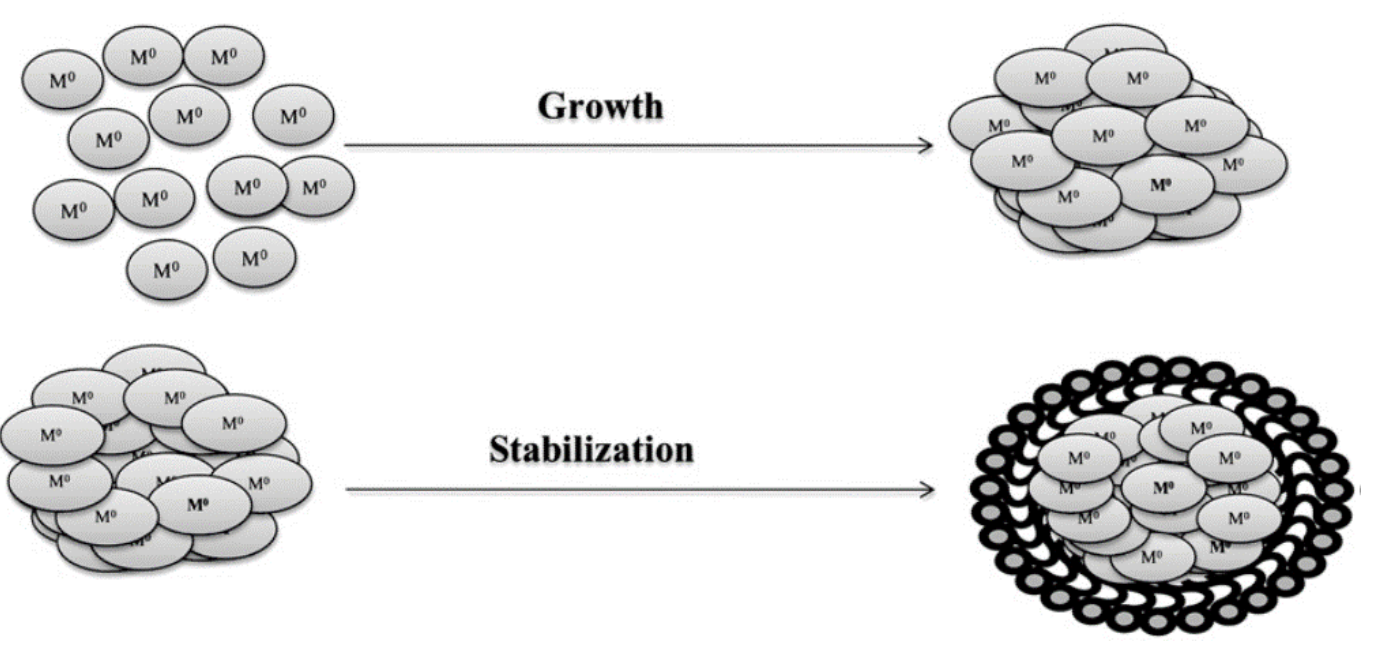

Figure 2. Various approaches for making nanoparticles and cofactor dependent bio-reduction. 
Madkour LH (2018) Ecofriendly green biosynthesized of metallic nanoparticles: Bio-reduction mechanism, characterization and pharmaceutical applications in biotechnology industry

proteins, sugars, amino acids, enzymes and other traces of metals. These metabolites are strongly involved in the bio-reduction process. The proposed reaction was $\mathrm{Au}^{+}$ions reduction into metallic $\mathrm{Au}^{\mathrm{o}}$ nanoparticles in the presence of metabolites and redox enzymes [18].

The reaction is given below.

$\mathrm{H} \mathrm{Au}^{+} \mathrm{Cl}_{4} \cdot 4 \mathrm{H}_{2} \mathrm{O}+$ Plant extracts $\rightarrow \mathrm{Au}^{\circ} \mathrm{NPs}+$ byproducts

Platinum: platinum is involved in the following reduction process such as

\section{$\mathrm{H}_{2} \mathrm{Pt}^{+} \mathrm{Cl}_{2} .6 \mathrm{H}_{2} \mathrm{O}+$ Plant extracts $\rightarrow \mathrm{Pt}^{\circ} \mathrm{NPs}+$ byproducts}

Copper: the copper nanoparticles are synthesized from plant extracts and the reduction mechanism was proposed by [19]:

\section{$\mathrm{CuSO}_{4} \cdot 5 \mathrm{H}_{2} \mathrm{O}+$ Plant metabolites $\rightarrow \mathrm{Cu}^{\circ} \mathrm{NPs}+$ byproducts}

Zinc oxide: A typical procedure was employed in $\mathrm{ZnO}$ nanoparticles production; the zinc nitrate was dissolved in the aloe plant extract to produce the nanosized particles. The method is as follows [20]:

Zinc nitrate + Plant extract $\rightarrow \mathrm{ZnO}+$ byproducts

Titanium oxide: Nano-sized $\mathrm{TiO}_{2}$ has been successfully produced by adding $\mathrm{TiO}(\mathrm{OH})_{2}$ solution to the suspension of Lactobacillus sp. The equation can be described as following:

$$
\text { Ti. }(\mathrm{OH})_{2} \rightarrow \mathrm{TiO}_{2}+\mathrm{H}_{2} \mathrm{O}
$$

\section{Factors influencing the synthesis of metallic nanoparticles}

Some environmental factors such as physical and chemical parameters controlled metallic crystal structure using the plant biomass as substrates. It determined the employment of growth conditions and obvious formation of different size of NPs such as spherical, triangular, hexagonal and rectangular.

There are different types of molecules that could act or be used as capping agents but some of the broadly classified green capping agents.

Moreover, the amino and carboxy groups present in the amino acids caused the reduction of $\mathrm{AuCl}_{4}^{-}$and coating of NP surface [21]. In another interesting study, Au nanochains were prepared via facile single step within $15 \mathrm{~min}$ in the presence of glutamic acid and histidine amino acids. The removal of amino acid molecules from (111) facet allows the linear aggregation of particles due to dipole-dipole interactions which arise as a result of the zwitterionic nature of amino acids.

The synthesis is carried out in the presence of water as a solvent thus, eliminating the use of toxic solvents [22]. One of the distinguishing features of polysaccharides is that they sharply accelerate the kinetics of sol-gel processes due to their catalytic effect [23]. They not only have been found to modify the structure and morphology of $\mathrm{TiO}_{2}$ but have induced a different phase where rutile phase has been obtained in the presence of chitosan whereas anatase in the presence of starch [24].

\section{Nanoparticle synthesis using microorganisms}

Some well-known examples of nanoparticles synthesized by microorganisms either intracellularly or extracellularly [25] are: synthesis of magnetite by magnetotactic bacteria and synthesis of siliceous material by radiolarians and diatoms. The green synthesis methods include synthesis of nanoparticles using microorganisms like bacteria, fungus, yeasts, plants and DNA [26]. Multiple species of bacteria and fungi have been investigated for the growth of nanoparticles of different composition and size, for example, synthesis of gold by Verticilliumsp, synthesis of CdS quantum dots using fungi etc.
In recent research, bacteria, including Pseudomonas deceptionensis [27], Weissella oryzae [28], Bacillus methylotrophicus [29], Brevibacterium frigoritolerans [30], and Bhargavaea indica [31], have been explored for silver and gold nanoparticle synthesis. Similar potential for producing nanoparticles has been showed by using several Bacillus and other species, including Bacillus licheniformis, Bacillus amyloliquefaciens, Rhodobacter sphaeroides [32], Listeria monocytogenes, Bacillus subtilis, and Streptomyces anulatus $[32,33]$. Various genera of micro-organisms have been reported for metal nanoparticle synthesis, including Bacillus, Pseudomo-nas, Klebsiella, Escherichia, Enterobacter, Aeromonas, Corynebacterium, Lactobacillus, Pseudomonas, Weissella, Rhodobacter, Rhodococcus, Brevibacterium, Streptomyces, Tricho-derma, Desulfovibrio, Sargassum, Shewanella, Plectonemaboryanum, Rhodopseudomonas, Pyrobaculum, and others [34].

\section{Results}

The proteins present in the alga acted as templating as well as stabilizing agent, thereby avoiding the use of surfactants, which are difficult to remove. The water-soluble pigments present in the extract were found to be responsible for the reduction and stabilization of the NPs [35]. The polysaccharides present in the aqueous extract of Sargassum muticum caused the reduction of ferric chloride solution, thereby leading to the formation of ferric oxide $\left(\mathrm{Fe}_{3} \mathrm{O}_{4}\right) \mathrm{NPs}$ with cubic morphology and average diameter of $18 \pm 4 \mathrm{~nm}$ [36]. Since, these are large molecules and amphiphilic in nature; they act as surfactant molecules, which causes not only concentration buildup of the surfactant at the surface and reduction of the surface tension, but also the orientation of the molecule at the surface [37]. The biogenic methods lead to the designing of NPs with interesting morphologies and varied sizes [18]. However, with time, on exposure of NPs the toxicity levels against alga increase, but the synthesized NPs show no toxicity when tested with cell lines of normal human cell [38]. The coating of biological molecules on the surface of NPs makes them biocompatible in comparison with the NPs prepared by chemical methods [39]. The biocompatibility of bio-inspired NPs offers very interesting applications in biomedicine and related fields [40]. These biomolecules are effective against cancer, diabetes, thrombosis, obesity, and other degenerative diseases and act as reducing as well as capping agents. Many previous reports are demonstrating that biosynthesized nanoparticle effectively controlled oxidative stress, genotoxicity and apoptosis related changes. Sigma Aldrich is currently the leading supplier of nanomaterials. BASF and Evonik Degussa are its close competitors, in particular in the offer of nanomaterials in cosmetics and personal hygiene (Table 1) [41].

\section{Characterization and commercial applications of biosynthesized nanoparticles}

Nanoparticles are generally characterized by their size, shape, surface area, and disparity [42]. Light wavelengths in the 300-800 $\mathrm{nm}$ are generally used for characterizing various metal nanoparticles in the size range of 2 to $100 \mathrm{~nm}$. The ratio of surface area to mass in nanometric particles is 1000 -fold greater than in micrometric particles [41]. Quantum dots are the materials, which in greatest extent use the quantum effects. Quantum effects also affect the ability to accept or donate electrical charge, which determines the catalytic ability [41]. In addition to potential benefits (antibiotic, antifungal and antiviral properties), silver nanoparticles (AgNPs) can trigger for instance undesirable and hazardous interactions with biological systems, thereby generating toxicity. Their properties can be majorly divided into physical and optical properties. Applications of NPs will particularly depend on 
Madkour LH (2018) Ecofriendly green biosynthesized of metallic nanoparticles: Bio-reduction mechanism, characterization and pharmaceutical applications in biotechnology industry

Table 1. Market for nanomaterials - global production in 2014 [41]

\begin{tabular}{|c|c|c|c|}
\hline Production & Nanoparticles & $\begin{array}{l}\text { Minimum global } \\
\text { production volume } \\
\text { [tons] }\end{array}$ & $\begin{array}{l}\text { Maximum global } \\
\text { production volume } \\
\text { [tons] }\end{array}$ \\
\hline $\begin{array}{l}\text { High volume } \\
\text { production }\end{array}$ & $\begin{array}{l}\text { Titanium dioxide } \\
\text { Zinc oxide } \\
\text { Silicon dioxide } \\
\text { Aluminium oxide } \\
\text { Carbon Nanotubes } \\
\text { Nanoclays } \\
\text { Cerium oxide }\end{array}$ & $\begin{array}{l}60,000 \\
32,000 \\
185,000 \\
5,000 \\
1,550 \\
25,000 \\
880\end{array}$ & $\begin{array}{l}150,00 \\
36,00 \\
1,400,000 \\
10,100 \\
1,950 \\
51,000 \\
1,400\end{array}$ \\
\hline $\begin{array}{l}\text { Low volume } \\
\text { production }\end{array}$ & $\begin{array}{l}\text { Quantum dots } \\
\text { Antimony tin oxide } \\
\text { Copper oxide Silver } \\
\text { Nanocellulose } \\
\text { Bismuth oxide } \\
\text { Cobalt oxide } \\
\text { Dendrimers } \\
\text { Fullerenes \& POSS } \\
\text { Graphene } \\
\text { Gold } \\
\text { Iron oxide } \\
\text { Magnesium oxide } \\
\text { Manganese oxide } \\
\text { Nickel } \\
\text { Zirconium oxide }\end{array}$ & $\begin{array}{l}4.5 \\
120 \\
290 \\
135 \\
400 \\
35 \\
5 \\
0.3 \\
40 \\
60 \\
1 \\
9 \\
15 \\
2 \\
5 \\
80\end{array}$ & $\begin{array}{l}9 \\
225 \\
570 \\
420 \\
1,350 \\
55 \\
<10 \\
1.25 \\
100 \\
80 \\
3 \\
45 \\
30 \\
3.5 \\
20 \\
300\end{array}$ \\
\hline
\end{tabular}

their physicochemical properties (size, shape, crystal structure or not, surface charge, solubility, etc.).

In summary, Table 2 depicts the compositions, shape and size of the NPs and the corresponding biomaterials adopted as the reduction agents reported during the last decade.

\section{Classical approaches of metallic nanoparticles}

Even today, the biological aspects of metallic gold nanoparticles (GNPs) are very useful to human health and cosmetics applications. Silver is used as wound healer agents and ulcer treatment [43].

The applications of NPs materials are numerous and now remarkably significant in human life and in industries [44]. The possibility of applying nanomaterials for use in agriculture, veterinary medicine, the food industry and cosmetology is also being explored. The group of materials of particular interest includes: nanoparticles of silver, gold, zinc, selenium, titanium dioxide and carbon nanotubes. Medical bioengineering is an area where nanotechnology has found many applications. In this area, nanotechnology is mainly used in the field of diagnostic tests - as a tool for the detection of diseases and their imaging and monitoring of pharmacological therapy (mainly the system of drug delivery and disposition in the human body). That results in the unmistakable increase in the level of biocompatibility of implants used. The beauty industry is another sector in which nanotechnology is used [45]. The harmful preservatives have been partially replaced by metal nanoparticles, in particular AgNPs

\section{Catalytic applications of NPs and waste water treatment}

There are also various eco-friendly nanoproducts available in commercial market with high efficiency such as water purifier, bone and teeth cement, facial cream and homemade products [46]. Biosynthesized NPs exhibit interesting size dependent catalytic properties due to high surface-to-area volume ratio. Pd NPs synthesized using soya leaf extract caused the degradation of azo dyes [47]. $\mathrm{Fe}_{3} \mathrm{O}_{4}$ NPs coated with soluble bio-based products (SBO) efficiently adsorbed crystal violet (CV) dye used as a model pollutant. Thus, these NPs could be used for the removal of pollutants in the water [48].

\section{Biosensing applications of NPs}

Recently, attention has been focused on the synthesis and application of nanocomposites for supercapacitors [49], which can have superior electrochemical performance than single structured materials. These encouraging results show great potential in terms of developing high-capacitive energy storage devices for practical applications [49].

\section{Cosmetics applications of NPs}

New dimension of metallic nanoparticles is used for different commercial applications mainly cosmetics, pharma coating materials and food preservatives.

\section{Nanoparticles in food industry}

In food industries, the food products gets high microbial contamination due to their various open scale processes such as in manufacturing, processing and shipping of raw materials.

\section{Pharmacological and biomedical applications of NPs}

Being super paramagnetic in nature, iron and iron oxide NPs find extensive usage in biomedical applications. Au NPs have proved to be important tool in many potential biomedical applications including an emerging alternative for life-threatening diseases, DNA modeling and biosensor applications, especially in cancer nanotechnology. Nanoparticles have proved to be a likely candidate for antimicrobial agent. AgNPs is a suitable promising agent to inhibit the growth of cancer cells via various mechanistic approaches; the hypothetical mechanism is shown in Figure 4.

The plant derived chemical constituents such as quinine, artemisinin and aromatic compound have been successfully used against resistant strains of malaria parasites. Anti-inflammatory is an important wound healing mechanism. Anti-inflammation is a cascade process that produces immune responsive compound.

The bio based nanoparticles are new and revolutionized to treat malignant deposit and without interfering the normal cells. Suman, et al. (2013) [50] reported that the green synthesis of silver nanoparticles exhibited a significant cytotoxic effect in HeLa cell lines compared to other chemical based synthetic drugs. Daisy and Saipriya's (2012) $[4,51]$ results showed that gold nanoparticles have good therapeutic effects against diabetic models. The gold nanoparticles treated diabetic model showed a decrease of $\mathrm{HbA}$ (glycosylated haemoglobin) level which is maintaining the normal range [52] explored the Sphaeranthus amaranthoides biosynthesized AgNPs inhibited a-amylase and acarbose sugar in diabetes induced animal model.

\section{Discussion}

Green biosynthesis [53] has been considered as one of the promising method for synthesis of nanopartilces because of their biocompatibility, low toxicity and eco-friendly nature [54]. The rich biodiversity and easy availability of plant entities have been highly explored for the nanomaterials synthesis [55]. The biosynthesis method employing plant extracts of Pelargonium graveolens, Medicagosativa, Azadirachta indica, Lemongrass, Aploevera, Cinnamomum Camphor [13] have drawn great attention as an alternative to conventional methods, because plants are found in abundance in nature. It is hydrophilic, biocompatible, non-toxic and used for coating of many metal NPs [56]. Feng, et al. explored the adsorption mechanism of amino acids and surfactants on to the (111) surface of gold using molecular dynamic simulation with the application of intermolecular potential CHARMMMETAL [57]. 
Madkour LH (2018) Ecofriendly green biosynthesized of metallic nanoparticles: Bio-reduction mechanism, characterization and pharmaceutical applications in biotechnology industry

Table 2. Algae mediated synthesis of metallic NPs.

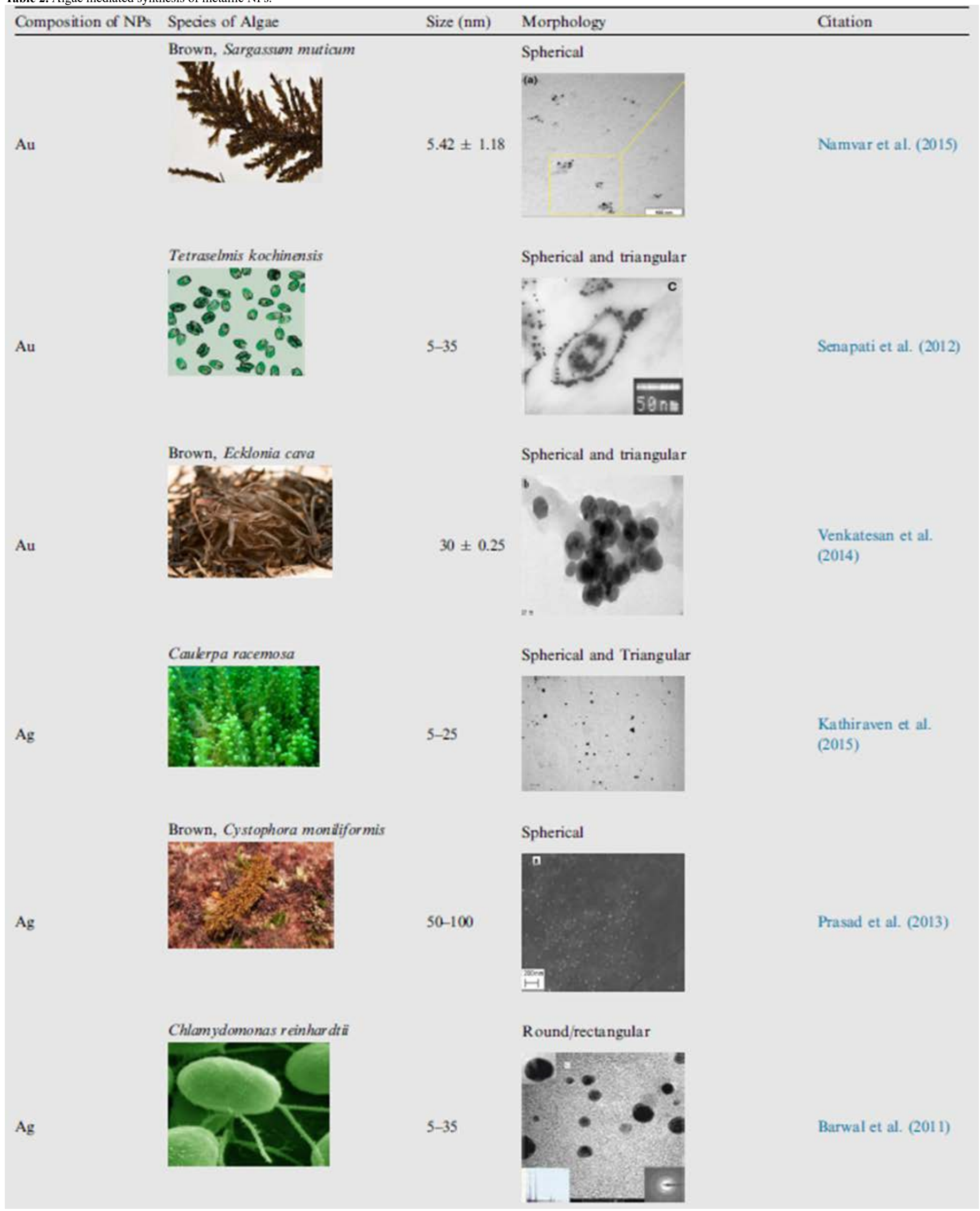


Madkour LH (2018) Ecofriendly green biosynthesized of metallic nanoparticles: Bio-reduction mechanism, characterization and pharmaceutical applications in biotechnology industry

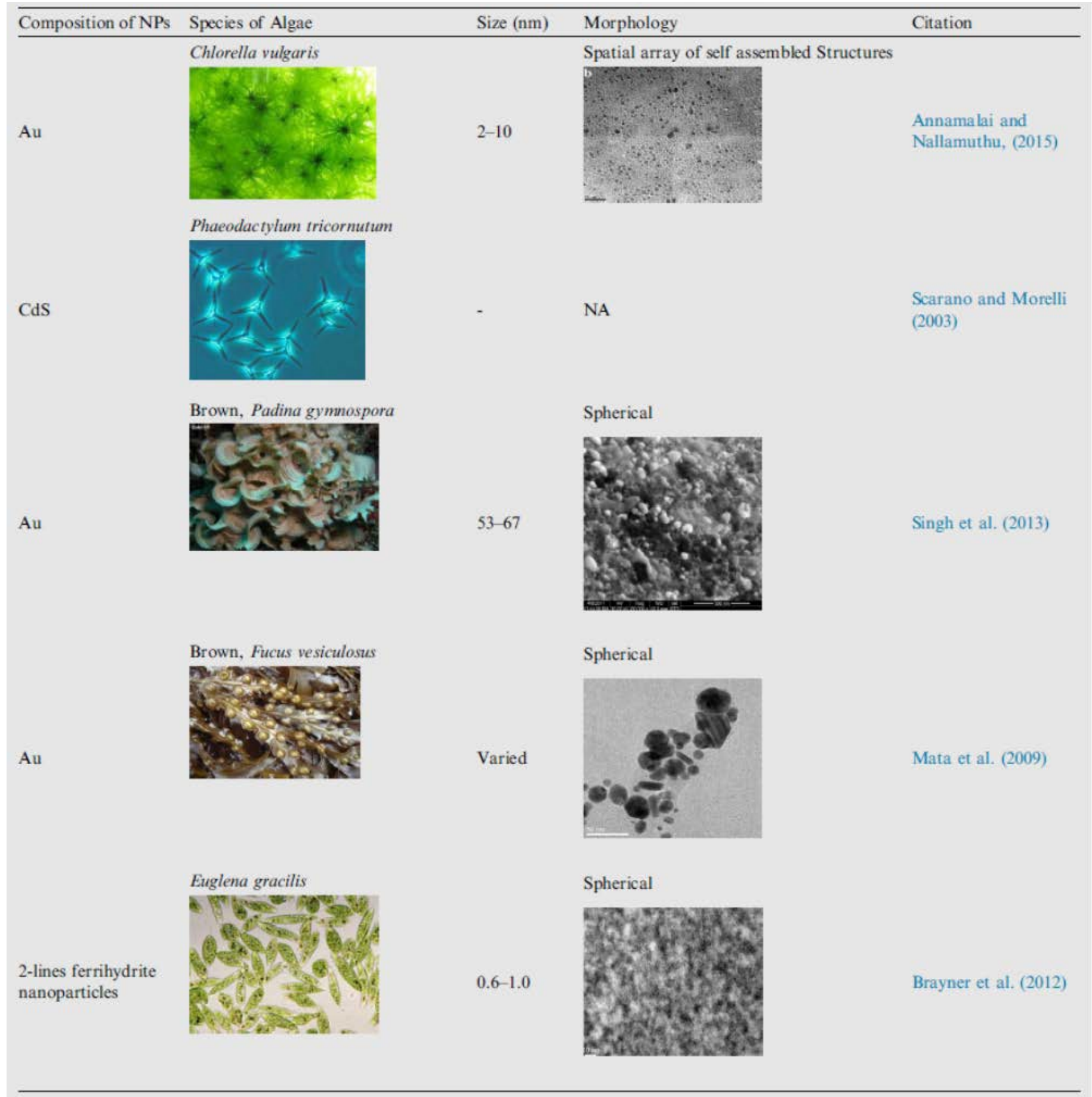

$\mathrm{NA}=$ not available.

The mechanism for the interaction of NPs with the specific membrane has been illustrated in Figure 5 [58].

As soon as NP comes in contact with the membrane of pathogenic microorganisms, there is dissolution and release of metal cations which inhibit respiratory enzymes and ATP production. There is reactive oxygen species (ROS) production which disrupts membrane integrity and other transport processes [58].

Anti-bactericidal activities of metallic nanoparticles, the reciprocal action of nanoparticles subsequently breaks the cell membrane and disturbs the protein synthesis mechanism in the bacterial system. Antifungicidal activities of metallic nanoparticles. The fungal cell membrane structure significant changes were observed by treating it with metallic nanoparticles. Antiplasmodial activity of metallic nanoparticles, this method has been more economical but less effective to control the target organisms in the health care sector.

These investigations suggest that the main mechanism of the synthesis of nanoparticles using bacteria depends on enzymes; Algae and most fungi containing important metabolites with higher 
Madkour LH (2018) Ecofriendly green biosynthesized of metallic nanoparticles: Bio-reduction mechanism, characterization and pharmaceutical applications in biotechnology industry

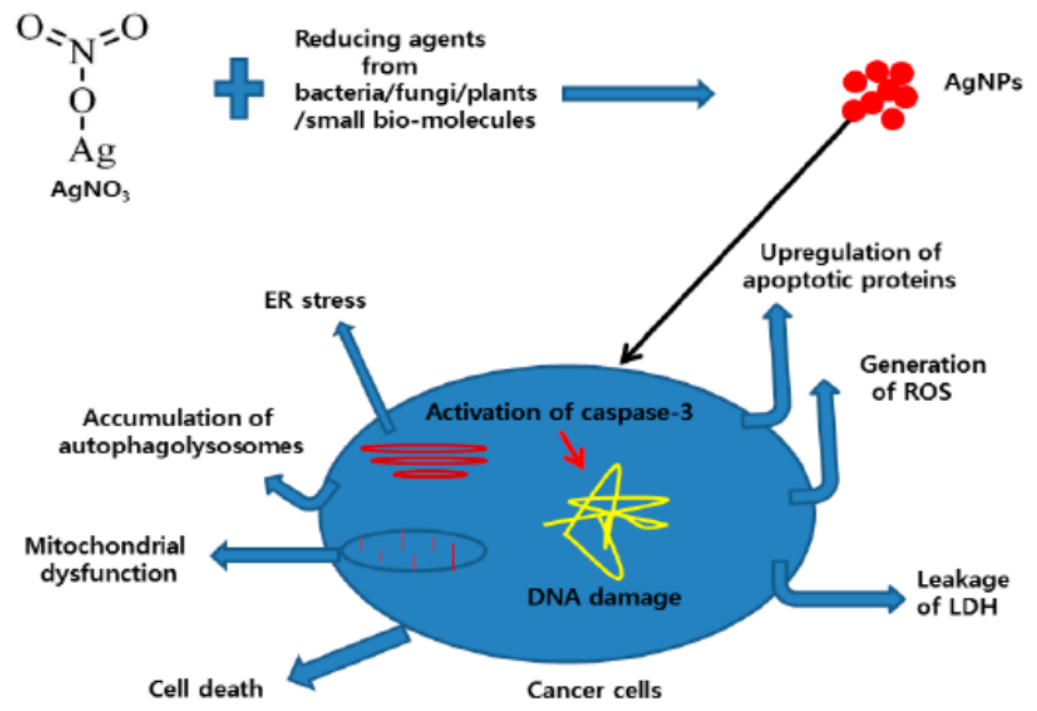

Figure 4. The possible mechanisms of AgNP-induced cytotoxicity in cancer cell lines. Endoplasmic reticulum stress(ER), lactate dehydrogenase (LDH), reactive oxygen species (ROS).

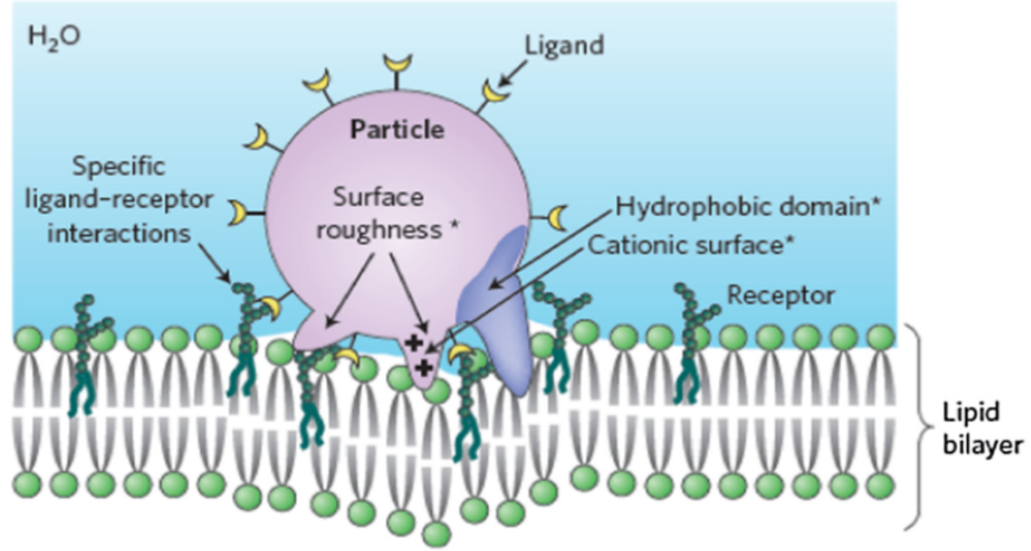

Figure 5. Representation of receptor-mediated uptake. This is the specific biological mechanism for particles interacting with the surface membrane and undergoing cellular uptake. The intrinsic NP characteristics that promote surface binding (roughness, hydrophobicity, cation charge) generally lead to nonspecific binding forces (marked by asterisks) that promote cellular uptake. In contrast, specific receptor-ligand interactions generally lead to endocytic uptake. A combination of nonspecific binding forces on the surface of spiked particles can lead to direct penetration of the surface membrane without the need to involve endocytic compartments. Reproduced with permission [58].

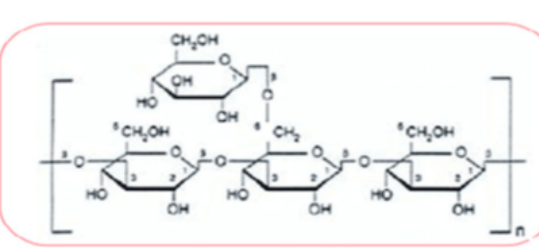

polysaccharides

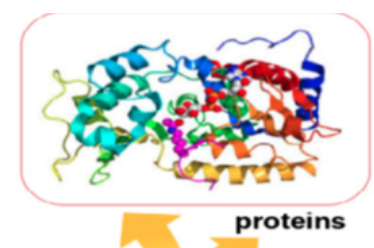

proteins

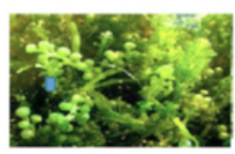

Algae

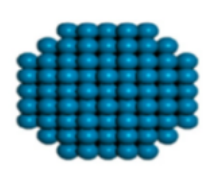

Nanoparticles
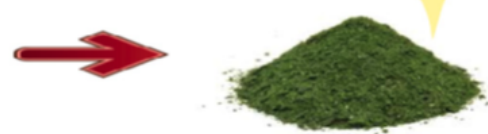

Algal extract
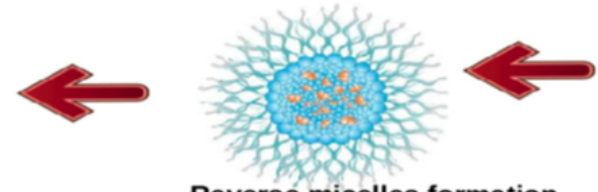

Reverse micelles formation

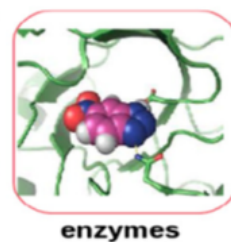

enzymes

Figure 6. Mechanism of biosynthesis of NPs using algae. 
Madkour LH (2018) Ecofriendly green biosynthesized of metallic nanoparticles: Bio-reduction mechanism, characterization and pharmaceutical applications in biotechnology industry

bioaccumulation ability and simple downstream processing are easy to culture for the efficient, low-cost, production of nanoparticles [59]. Moreover, compared with bacteria, fungi have higher tolerances to, and uptake competences for, metals, particularly in terms of the high wallbinding capability of metal salts with fungal biomass for the high-yield production of nanoparticles [59]. Three possible mechanisms have been proposed to explain the mycosynthesis of metal nanoparticles: nitrate reductase action; electron shuttle quinones; or both [59]. Fungal enzymes, such as the reductase enzymes from Penicillium species and Fusarium oxysporum, nitrate reductase, and /-NADPH-dependent reductases, were found to have a significant role in nanoparticle synthesis, similarly to the mechanism found in bacteria. The synthesis of nanoparticles using actinomycetes has not been well explored, even though actinomycetes-mediated nanoparticles have good monodispersity and stability and significant biocidal activities against various pathogens $[60,61]$. The simple mechanism in Figure 6 explains that enzymes and functional groups present in the cell walls of algae form complexing agents with the precursors thereby, causing reduction and deposition of metal/metal oxide NPs at ambient conditions.

\section{Cytotoxic}

Cytotoxic drugs act by directly killing selected cells, affecting both the growth and behavior of remaining cells to treat unwanted malignancies and tumors. Cytotoxic can be used to treat various ailments including rheumatoid arthritis, and systemic lupus erythematous. They are commonly used in oncology therapeutics, which represent one of the fastest growing segments of the pharmaceutical and biotechnology industry.

While cytotoxic drugs have widespread treatment potential, the successful and safe manufacturing of cytotoxic drugs requires a highly skilled team of experts and well controlled manufacturing facilities. Lonza currently operates GMP production suites for gram-scale cytotoxic production and recently invested CHF 24 million for multikilogram-scale production capacity at our site in Visp, Switzerland. Focus on safety of supply when meeting the clinical and commercial scale demands.

\section{Investments are been made for the new cytotoxic facility}

The investment consists of 3 parts:

- Fermentation and chemical capabilities of all scales to give customers the opportunity to manufacture complex cytotoxins with confidence at Lonza. The site will have the lowest occupational exposure limits (OELs) to safeguard employees and the environment.

- SSP build-out: Investment in infrastructure and clean rooms including gowning area and airlocks fully dedicated to the chemical production and isolation of cytostatic and cytotoxic compounds. The entire setup will be constructed in a modular and very flexible way in order to accommodate a wide range of product / process requirements. The investment will include a new building fully dedicated to the microbial fermentation of cytotoxic compounds. Main equipment for this building will include fermenters in the range of 50 to 1000 liter and a filtration unit.

- Upgrade of existing $15 \mathrm{~m}^{3}$ fermenter in Visp, Switzerland so that it can be used for the production of larger amounts of highly active compounds.

\section{References}

1. Madkour LH (2017) Vision for life sciences: interfaces between nanoelectronic and biological systems. Glob Drugs Therap 2: 1-4.
2. Pereira L, Mehboob F, Stams AJ, Mota MM, Rijnaarts HH, et al. (2015) Metallic nanoparticles: microbial synthesis and unique properties for biotechnological applications, bioavailability and biotransformation. Crit Rev Biotechnol 35: 114-128. [Crossref]

3. Taniguchi N (1974) On the basic concept of nanotechnology. In: Proc. of International Conference on Precision Engineering (ICPE), Tokyo, Japan, 18-23.

4. Madkour LH (2017) Advanced AuNMs as nanomedicine's central goals capable of active targeting in both imaging and therapy in biomolecules. Glob Drugs Therap 2: $1-12$.

5. Kwon SJ, Bard AJ (2012) DNA analysis by application of Pt nanoparticle electrochemical amplification with single label response. J Am Chem Soc 134: 10777 10779. [Crossref]

6. Chiu CY, Ruan L, Huang Y (2013) Bimolecular specificity controlled nanomaterial synthesis. Chem Soc Rev 42: 2512-2527. [Crossref]

7. Mikami Y, Dhakshinamoorthy A, Alvaro M, Garcia H (2013) Catalytic activity of unsupported gold nanoparticles. Catal Sci Technol 3: 58-69.

8. Waghmare SR, Mulla MN, Marathe SR, Sonawane KD (2015) Ecofriendly production of silver nanoparticles using Candida utilis and its mechanistic action against pathogenic microorganisms. 3 Biotech 5: 33-38. [Crossref]

9. Azizi S, Ahmad MB, Namvar F, Mohamad R (2014) Green biosynthesis and characterization of zinc oxide nanoparticles using brown marine macroalga Sargassum muticum aqueous extract. Mater Lett 116: 275-277.

10. Dubey M, Bhadauria S, Kushwah B (2009) Green synthesis of nanosilver particles from extract of Eucalyptus hybrida (safeda) leaf. Dig J Nanomater Biostruct 4: 537-43.

11. Huang JL, Li QB, Sun DH, Lu YH, Su YB, et al. (2007) Biosynthesis of silver and gold nanoparticles by novel sundried Cinnamomum camphora leaf. Nanotechnolog 18

12. Kuppusamy P, Yusoff MM, Maniam GP, Govindan N (2016) Biosynthesis of metallic nanoparticles using plant derivatives and their new avenues in pharmacological applications - An updated report. Saudi Pharm J 24: 473-484. [Crossref]

13. Mittal AK, Chisti Y, Banerjee UC (2013) Synthesis of metallic nanoparticles using plant extracts. Biotechnol Adv 31: 346-356. [Crossref]

14. Momeni K, Attariani H, LeSar RA (2016) Structural transformation in monolayer materials: a 2D to 1D transformation. Phys Chem Chem Phys 18: 19873-19879.

15. Syed A, Saraswati S, Kundu GC, Ahmad A (2013) Biological synthesis of silver nanoparticles using the fungus Humicola sp. And evaluation of their cytoxicity using normal and cancer cell lines. Spectrochim Acta A Mol Biomol Spectrosc 114: 144-147. [Crossref]

16. Thakkar KN, Mhatre SS, Parikh RY (2010) Biological synthesis of metallic nanoparticles. Nanomedicine 6: 257-262. [Crossref]

17. Tripathy A, Raichur AM, Chandrasekaran N, Prathna TC, Mukherjee A (2010) Process variables in biomimetic synthesis of silver nanoparticles by aqueous extract of Azadirachta indica (Neem) leaves. J Nanopart Res 12: 237-246.

18. Schröfel A, Kratošová G, Šafařík I, Šafaříková M, Raška I, et al. (2014) Applications of biosynthesized metallic nanoparticles- a review. Acta Biomater 10: 4023-4042. [Crossref]

19. Ramanathan R, Field MR, O'Mullane AP, Smooker PM, Bhargava SK, et al. (2013) Aqueous phase synthesis of copper nanoparticles: a link between heavy metal resistance and nano- particle synthesis ability in bacterial systems. Nanoscale 21: 2300-2306. [Crossref]

20. Sangeetha G, Rajeshwari S, Venckatesh R (2011) Green synthesis of zinc oxide nanoparticles by aloe barbadensis miller leaf extract: structure and optical properties. Mater Res Bull 46, 2560-2566.

21. Maruyama T, Fujimoto Y, Maekawa T (2015) Synthesis of gold nanoparticles using various amino acids. J Colloid Interf Sci 447: 254-257. [Crossref]

22. Duan H, Wang D, Li Y (2015) Green chemistry for nanoparticle synthesis. Chem Soc Rev 44: 5778-5792. [Crossref]

23. Boury B, Plumejeau S (2015) Metal oxides and polysaccharides: an efficient hybrid association for materials chemistry. Green Chem 17: 72-88.

24. Bao SJ, Lei C, Xu MW, Cai CJ, Cheng CJ, et al. (2013) Environmentally-friendly biomimicking synthesis of $\mathrm{TiO}_{2}$ nanomaterials using saccharides to tailor morphology, crystal phase and photocatalytic activity. Cryst Eng Comm 15: 4694-4699. 
Madkour LH (2018) Ecofriendly green biosynthesized of metallic nanoparticles: Bio-reduction mechanism, characterization and pharmaceutical applications in biotechnology industry

25. Bansal V, Bharde A, Ramanathan R, Bhargava SK (2012) Inorganic materials using 'unusual'microorganisms. Adv Colloid Interface Sci 179: 150-168. [Crossref]

26. Madkour LH (2017) Biotechnology of Nucleic Acids Medicines as Gene Therapeutics and Their Drug Complexes. Chron Pharma Sci 1: 204 -253. [Crossref]

27. Jo JH, Singh P, Kim YJ, Wang C, Mathiyalagan R, et al. (2015) Pseudomonas deceptionensis DC5-medi-ated synthesis of extracellular silver nanoparticles. Artif Cells Nanomed Biotechnol 44: 1576-1581. [Crossref]

28. Singh P, Kim YJ, Wang C, Mathiyalagan R, Yang DC (2015) Weissella oryzae DC6facilitated green synthesis of silver nanoparticles and their antimicrobial potential. Artif Cells Nanomed Biotechnol 44: 1569-1575. [Crossref]

29. Wang C, Kim YJ, Singh P, Mathiyalagan R, Jin Y, et al. (2015) Green synthesis of silver nanoparticles by Bacillus methylotrophicus, and their antimicrobial activity. Artif Cells Nanomed Biotechnol 44: 1127-1132. [Crossref]

30. Singh P, Kim YJ, Singh H, Wang C, Hwang KH, et al. (2015) Biosynthesis, characterization, and antimicrobial applications of silver nanoparticles. Int J Nanomed 10: 2567-2577. [Crossref]

31. Singh P, Kim YJ, Wang C, Mathiyalagan R, Yang DC (2015) Microbial synthesis of flower-shaped gold nanoparticles. Artif Cells Nanomed Biotechnol 44: 1469-1474. [Crossref]

32. Elbeshehy EK, Elazzazy AM, Aggelis G (2015) Silver nanoparticles synthesis mediated by new isolates of Bacillus spp., nanoparticle characterization and their activity against bean yellow mosaic virus and human pathogens. Front Microbiol 6: 453. [Crossref]

33. Soni N, Prakash S (2015) Antimicrobial and mosquitocidal activity of microbial synthesized silver nanoparticles. Parasitol Res 114: 1023-1030. [Crossref]

34. Li X, Xu H, Chen ZS, Chen G (2011) Biosynthesis of nanoparticles by microorganisms and their applications. J Nanomater 2011: 270974.

35. Nagarajan S, Arumugam Kuppusamy K (2013) Extracellular synthesis of zinc oxide nanoparticle using seaweeds of Gulf of Mannar, India. J Nanobiotechnol 11: 39. [Crossref]

36. Mahdavi M, Namvar F, Ahmad MB, Mohamad R (2013) Green biosynthesis and characterization of magnetic iron oxide $\left(\mathrm{Fe}_{3} \mathrm{O}_{4}\right)$ nanoparticles using seaweed (Sargassum muticum) aqueous extract. Molecules 18: 5954-5964. [Crossref]

37. Liu L, Shao Z, Ang HM, Tade MO, Liu S (2014) Are microorganisms indispensable in green microbial nanomaterial synthesis? RSC Adv 4: 14564-14568.

38. Parial D, Pal R (2015) Biosynthesis of monodisperse gold nanoparticles by green alga Rhizoclonium and associated biochemical changes. J Appl Phycol 27: 975-984.

39. Hakim LF, Portman JL, Casper MD, Weimer AW (2005) Aggregation behavior of nanoparticles in fluidized beds. Powder Technol 160: 149-160.

40. Huang J, Lin L, Sun D, Chen H, Yang D, et al. (2015) Bioinspired synthesis of metal nanomaterials and applications. Chem Soc Rev 44: 6330-6374.

41. Nanomaterials (2015) The global market, Forecast from 2010 to 2025, Future markets, Ed. 2.

42. Shahverdi AR, Shakibaie M, Nazari P (2011) Basic and practical procedures for microbial synthesis of nanoparticles. In: Rai M, Duran N, editors. Metal nanoparticles in microbiology. Berlin, 177-197.

43. Singh S, Saikia JP, Buragohain AK (2013) A novel 'green' synthesis of colloidal silve nanoparticles (SNP) using Dillenia indica fruit extract. Colloids Surf B Biointerfaces 102: 83-85. [Crossref]
44. Gaillet S, Rouanet JM (2015) Silver nanoparticles: Their potential toxic effects after oral exposure and underlying mechanisms -A review. Food Chem Toxicol 77: 58-63. [Crossref]

45. Sharma A, Kumar SM, Mahadevan N (2012) Nanotechnology: a promising approach for cosmetics. Int J Recent Adv Pharm Res 2: 54-61. [Crossref]

46. Kouvaris P, Delimitis A, Zaspalis V, Papadopoulos D, Tsipas SA, et al. (2012) Green synthesis and characterization of silver nanoparticles produced using Arbutus unedo leaf extract. Mater Lett 76: 18-20.

47. Petla RK, Vivekanandhan S, Misra M, Mohanty AK, Satyanarayana N (2012) Soybean (Glycine Max) leaf extract based green synthesis of palladium nanoparticles. $J$ Biomater Nanobiotechnol 3: 14-19.

48. Parker HL, Dodson JR, Budarin VL, Clark JH, Hunt AJ (2015) Direct synthesis of Pd nanoparticles on alginic acid and seaweed supports. Green Chem 17: 2200-2207.

49. Kim M, Choi J, Oh I, Kim J (2016) Design and synthesis of ternary $\mathrm{Co}_{3} \mathrm{O}_{4} /$ carbon coated $\mathrm{TiO}_{2}$ hybrid nanocomposites for asymmetric supercapacitors. Phys Chem Chem Phys 18: 19696-19704. [Crossref]

50. Suman TY, Rajasree SR, Kanchana A, Elizabeth SB (2013) Biosynthesis, characterization and cytotoxic effect of plant mediated silver nanoparticles using Morinda citrifolia root extract. Colloids Surf B Biointerfaces 106: 74-78. [Crossref]

51. Daisy P, Saipriya K (2012) Biochemical analysis of Cassia fistula aqueous extract and phytochemically synthesized gold nanoparticles as hypoglycemic treatment for diabetes mellitus. Int J Nanomed 7: 1189-1202. [Crossref]

52. Swarnalatha C, Rachela S, Ranjan P, Baradwaj P (2012) Evaluation of invitro antidiabetic activity of Sphaeranthus Amaranthoides silver nanoparticles. Int J Nanomat. Biostr 2: 25-29.

53. Mehata MS (2015) Enhancement of charge transfer and quenching of photoluminescence of capped CdS quantum dots. Sci Rep 5: 12056. [Crossref]

54. Malik P, Shankar R, Malik V, Sharma N, Mukherjee TK (2014) Green chemistry based benign routes for nanoparticle synthesis. J Nanopart 2014: 302429.

55. Mondal S, Roy N, Laskar RA, Sk I, Basu S (2011) Biogenic synthesis of Ag, Au and bimetallic $\mathrm{Au} / \mathrm{Ag}$ alloy nanoparticles using aqueous extract of mahogany (Swietenia mahogani JACQ.) leaves. Colloids Surf B Biointerfaces 82: 497-504. [Crossref]

56. Cheng F, Betts JW, Kelly SM, Schaller J, Heinze T (2013) Synthesis and antibacteria effects of aqueous colloidal solutions of silver nanoparticles using aminocellulose as a combined reducing and capping reagent. Green Chem 15: 989-998.

57. Feng J, Pandey RB, Berry RJ, Farmer BL, Naik RR, et al. (2011) Adsorption mechanism of single amino acid and surfactant molecules to $\mathrm{Au} 111$ surfaces in aqueous solution: design rules for metal-binding molecules. Soft Matter 7: 2113-2120.

58. Nel AE, Mädler L, Velegol D, Xia T, Hoek EM, et al. (2009) Understanding biophysicochemical interactions at the nano-bio interface. Nat Mater 8: 543-557. [Crossref]

59. Alghuthaymi MA, Almoammar H, Rai M, Said-Galiev E, Abd-Elsalam KA, et al (2015) Myconanoparticles: synthesis and their role in phytopathogens management. Biotechnol Biotechnol Equip 29: 221-236. [Crossref]

60. Golinska P, Wypij M, Ingle AP, Gupta I, Dahm H, et al. (2014) Biogenic synthesis of metal nanoparticles from actinomycetes: biomedical applications and cytotoxicity. Appl Microbiol Biotechnol 98: 8083-8097. [Crossref]

61. Madkour LH (2018) Biogenic-Biosynthesis Metallic Nanoparticles (NPs) and Their Applications in Biotechnology. Chronicles Pharm Sci.

Copyright: (C2018 Madkour LH. This is an open-access article distributed under the terms of the Creative Commons Attribution License, which permits unrestricted use, distribution, and reproduction in any medium, provided the original author and source are credited. 